\title{
Who Needs More Sleep? Comparing Undergraduate and Graduate Students' Sleep Habits in a National U.S. Sample
}

\author{
Sara B. Oswalt, MPH, $\mathrm{PhD}^{1} \&$ Tammy J. Wyatt, $\mathrm{PhD}, \mathrm{CHES}^{1}$ \\ ${ }^{1}$ Department of Kinesiology, Health and Nutrition, University of Texas at San Antonio, San Antonio, TX \\ Correspondence: Sara B. Oswalt, Department of Kinesiology, Health and Nutrition, One UTSA Circle, University of \\ Texas at San Antonio, San Antonio, TX 78249. Phone +1 210458 6227, FAX +1 210- 458 5873, email: \\ sara.oswalt@utsa.edu
}

Received: November 18, 2014

Accepted: December 12, $2014 \quad$ Online Published: December 20, 2014

doi:10.5430/ijhe.v4n1p77

URL: http://dx.doi.org/10.5430/ijhe.v4n1p77

\begin{abstract}
Sleep disorders and deficits are a national U.S. health concern, and college students report more sleep difficulties than the general population. Most published studies examine college students as a homogenous population or focus on professional (e.g. medical) students. This study compares sleep patterns of undergraduate and graduate students from a national U.S. sample using the American College Health Association-National College Health Assessment (ACHA-NCHA) II survey. Graduate students on average reported better sleep behaviors; however, graduate students' sleep habits were still poor and these students could also benefit from intervention.
\end{abstract}

Keywords: College students, Sleep, Health, Graduate students, American College Health Association-National College Health Assessment II

\section{Introduction}

The image of someone staying up all night to prepare for an exam, finish a paper or hang out with friends is often considered a typical college student experience. Numerous studies have documented concern about sleep patterns of college students (Buboltz, Brown, \& Soper, 2001; Buboltz et al., 2009; Forquer, Camden, Gabriau, \& Johnson, 2008; Gaultney, 2010; Gilbert \&Weaver, 2010; Orzech, Salafsky, \& Hamilton, 2011), and some show links between sleep disturbances and decreased academic success, such as GPA (Gaultney, 2010; Taylor, Vatthauer, Bramoweth, Ruggero \& Roane, 2011; Thacher, 2008) and academic motivation (Edens, 2006). In fact, some have found a higher correlation between academic problems and sleep than alcohol use, stress, depression, colds or flu (Prichard, Cunningham \& Broek, 2013). Likewise, it is well documented that stress and other mental health issues pose challenges for and are increasing among college students (Eisenberg, Gollust, Golberstein, \& Hefner, 2007; Gallagher, 2011; Hyun, Quinn, Madon, \& Lustig, 2006). Such mental health concerns may impede sleep patterns; for example, Wyatt and Oswalt (2013) found that among a nationally representative sample of college students, approximately $25 \%$ of undergraduate students and $20 \%$ of graduate students identified sleep difficulties as a major concern within the last 12 months.

In comparison to undergraduate students, few studies specifically examine graduate students and their sleep experiences. Many of the published literature on graduate students focus on non-US students or have a specific professional school focus, such as medical school. With U.S. participants, only Forquer and colleagues have included graduate students in their sample and found no differences between undergraduate and graduate students. This lack of consideration or even examination of graduate students is a frequent occurrence in health related studies (Bulmer, Irfan, Barton, Vancour, \& Breny, 2010). Assumptions are made by researchers and higher education administrators alike that graduate students are more mature and committed to their studies than undergraduates and this difference precludes the possibility of unhealthy or high-risk behaviors in graduate students (Bulmer et al., 2010). The findings of those studies that have examined health issues in both graduate and undergraduate student populations (Bulmer et al., 2010; Nelson, Lust, Story, \& Ehlinger, 2008; Meilman, 1993) do not support this assumption.

In addition, sleep disorders and sleep deficits are a national issue (Centers for Disease Control and Prevention (CDC), 2011) and the amount of sleep individuals get has decreased in the last 20 years (CDC, 2005). Furthermore, anecdotal reports of graduate students balancing additional priorities of work and family with academic responsibilities justifies the need for higher education administrators and student affairs professionals to be aware of 
sleep issues among graduate students as well as the undergraduate population. Campus educational and programming efforts may need to be modified if there are differences in sleep issues. In general, the issue of sleep should be a priority for higher education administrators because sleep difficulties can significantly influence student retention rates (Bray, Braxton, \& Sullivan, 1999; Strahan, 1999). The current study will contribute to the body of knowledge relating to college student sleep patterns by comparing the sleep experiences of graduate and undergraduate students through a secondary data analysis of a national sample.

\section{Method}

\subsection{Procedure and Participants}

Authors obtained approval and subsequently a dataset from American College Health Association (ACHA) to conduct this study on the most recently available American College Health Association-National College Health Assessment (ACHA-NCHA) II data set (Fall 2009) (ACHA, 2010b). This data set contains information collected from 34,208 undergraduate and graduate students enrolled part time and full time at 57 two- and four-year universities (ACHA, 2010a). Only colleges and universities that randomly select students or that survey students from randomly selected classrooms are included in the ACHA-NCHA database. The mean response proportion for this data set was $36 \%$ and the median response proportion was $23 \%$, with much higher rates for paper administration (mean response proportion 90\%) versus Web survey administration (mean response rate $21 \%$ ). This low response rate and not being a true random sample of U.S. college students does affect generalizability. But, at the same time, previous studies have demonstrated that the ACHA-NCHA provides similar results to nationally representative surveys (ACHA, 2004). The authors secured institutional review board (IRB) approval to perform a secondary analysis on this data set.

For the purposes of this study, inclusion/exclusion criteria were applied to ensure that the sample related to the research focus. Students who did not identify their classification as an undergraduate or graduate/professional student were not included in the analyses; therefore, students who indicated "not seeking a degree" or "other" were not included. Individuals who did not respond to the sleep-related items that were used as dependent variables were excluded. Likewise, individuals who were 50 years old or older were not included as the majority of college students $(96.2 \%)$ are under 50 regardless of status as an undergraduate or graduate student (U.S. Department of Education National Center for Education Statistics, 2011). In addition, some sleep research has indicated differences in sleep patterns of older individuals compared to those middle age and younger (Ohayon, Carskadon, Guilleminault, \& Vitiello 2004). Respondents attending universities outside the U.S. were also excluded as sleep patterns for adolescents differ between world regions (Gradisar, Gardner, \& Dohnt, 2011).

After applying the inclusion/exclusion criteria, the resulting sample was 26,681 students from 55 different universities and all regions of the U.S. Most student respondents were enrolled in a 4-year college or university $(94.6 \%, \mathrm{n}=25,233)$. Almost two-thirds $(61.9 \%, \mathrm{n}=16,516)$ attended public institutions, with $12.2 \%(\mathrm{n}=3,255)$ attending religiously affiliated institutions. Most participants were undergraduate students $(88.9 \%, \mathrm{n}=23,721)$. The average age for undergraduate students was 20.84 years $(\mathrm{SD}=4.31)$ compared to 27.32 years $(\mathrm{SD}=5.95)$ for graduate students.

Between graduate and undergraduate students, there were significant differences in sex $(64.9 \%$ of undergraduates were female compared to $58.6 \%$ of graduate respondents, $\chi^{2}(1)=44.03, p<.001$ ); ethnicity (higher percentage of those identifying as Asian/Pacific Islander in the graduate population (28.8\% compared to $8.4 \%$ ) which resulted in lower percentages of all other ethnic groups in the graduate population); full time status ( $95.4 \%$ of undergraduates compared to $84.8 \%$ of graduate students, $\left.\chi^{2}(1)=561.76, p<.001\right)$; and international status $(35.6 \%$ of graduate students versus $7.3 \%$ of undergraduate students, $\left.\chi^{2}(1)=2,242.34, p<.001\right)$. Graduate students were also more likely to be in a relationship and living together compared to undergraduate students (36.7\% vs. $13.2 \%)$ and live off campus $(73.8 \%$ compared to $30.6 \%)$. The number of hours per week spent working or volunteering was also examined; Mann Whitney U revealed that there was no significant difference in the hours volunteered but that graduate students worked significantly more hours per week than undergraduate students.

\subsection{Measures}

The ACHA-NCHA II includes demographic items as well as items associated with a variety of health behaviors. While there are 66 items related to health and health outcomes, most items were not relevant to the current study's emphasis. The authors identified six sleep-related items that focused on sleep habits and ten relevant demographic items including age, sex, ethnicity, year in school, relationship status, residence, hours worked and volunteered per week, and other student status categories (e.g., full- or part-time student, international). Most demographic items 
were only used to report frequencies to better understand the participants of this study. The only significant demographic item was if individuals were undergraduate or graduate students.

The participants were asked six questions related to sleep experiences within the last seven days. Five questions asked how many days out of the last seven the participants experienced the following: "enough sleep to feel rested"; "awakened too early in the morning and could not get back to sleep"; "felt tired, dragged out, or sleepy during the day"; "gone to bed because you just could not stay awake any longer"; and "an extremely hard time falling asleep." Responses for these questions ranged from 0 days to 7 days. One additional question asked if respondents had a problem with sleepiness in the last seven days. Possible responses were: "not a problem at all"; "a little problem"; "more than a little problem"; "a big problem"; or "a very big problem." Because these are single-items that measure behavior, psychometric analyses such as reliability and validity were not conducted in the current study.

\subsection{Analysis}

Descriptive analyses were calculated for demographic data. For the five sleep questions with interval data (number of days), a multivariate GLM procedure was conducted. To examine the item with ordinal data, a cross-tabulation was conducted to determine Mann Whitney U. To control for Type I error, the Bonferroni adjustment was performed $(.05 / 2)$ setting statistical significance at $p<.025$.

\section{Results}

Regarding the study focus, graduate students on average reported better sleep behaviors than undergraduate students. When asked how many days in the last seven they received enough sleep to feel rested, graduate students reported an average of $3.47(\mathrm{SD}=2.01)$ while undergraduates averaged $2.94(\mathrm{SD}=1.90)$.

Table 1. Means for Last Seven Days

\begin{tabular}{cccc}
\hline & & $\mathrm{M}$ & $\mathrm{SD}$ \\
\hline Enough sleep to feel rested & Graduate & 3.47 & 2.01 \\
& Undergraduate & 2.94 & 1.90 \\
Awakened too early & Graduate & 0.91 & 1.50 \\
& Undergraduate & 1.01 & 1.56 \\
Felt tired/sleepy during the day & Graduate & 2.77 & 2.04 \\
Gone to bed because could not stay awake & Undergraduate & 3.40 & 2.07 \\
& Graduate & 1.72 & 1.94 \\
Extremely hard time falling asleep & Undergraduate & 1.95 & 2.03 \\
& Graduate & 1.09 & 1.71 \\
& Undergraduate & 1.58 & 2.04 \\
\hline
\end{tabular}

For all other results -- awakened too early, feeling tired and sleepy during the day, going to bed because they could not stay awake, and having an extremely hard time falling asleep -- graduate students consistently reported lower averages than undergraduate students. Table 1 contains means and standard deviations for all five items. 
Table 2. Correlation between Sleep Variables, Age and Student Classification

\begin{tabular}{|c|c|c|c|c|c|c|}
\hline & 2. & 3. & 4. & 5. & 6. & Age \\
\hline 1. Enough sleep to feel rested & $-.169^{* *}$ & $-.574^{* *}$ & $-.259^{* *}$ & $-.251^{* *}$ & $.086^{* *}$ & $.036^{* *}$ \\
\hline 2. Awakened too early & & $.225^{* *}$ & $.183^{* *}$ & $.358^{* *}$ & $-.021^{*}$ & $.075^{* *}$ \\
\hline 3. Felt tired/sleepy during the day & & & $.421^{* *}$ & $.310^{* *}$ & $-.095^{* *}$ & $-.049^{* *}$ \\
\hline 4. Gone to bed because could not stay awake & & & & $.090^{* *}$ & $-.035^{* *}$ & $-.018^{*}$ \\
\hline 5. Extremely hard time falling asleep & & & & & $-.077^{* *}$ & $-.017^{*}$ \\
\hline 6. Graduate - Undergraduate status & & & & & & $.410^{* *}$ \\
\hline
\end{tabular}

Table 2 contains correlations for the five variables that examine sleep experiences in the last seven days, plus the demographic characteristics of classification and age. All sleep items were significantly correlated with each other and with age and graduate versus undergraduate status. The correlations between the sleep items were much higher than the correlation between any of the items and graduate-undergraduate status.

Table 3. Summary of Multivariate GLM Results for Graduate versus Undergraduate (G v UG) Status

\begin{tabular}{|c|c|c|c|c|c|c|}
\hline & & $\mathrm{df}$ & SS & $\mathrm{M}_{\mathrm{s}}$ & $\mathrm{F}$ & $\eta^{2}$ \\
\hline \multirow[t]{2}{*}{ Enough sleep to feel rested } & GvUG & 1 & 595.37 & 595.37 & $162.75^{*}$ & .006 \\
\hline & Error & 26,678 & $97,595.12$ & 3.66 & & \\
\hline \multirow[t]{2}{*}{ Awakened too early } & Gv UG & 1 & 208.17 & 208.17 & $86.77^{*}$ & .003 \\
\hline & Error & 26,678 & $64,002.25$ & 2.40 & & \\
\hline \multirow[t]{2}{*}{ Felt tired/sleepy during the day } & Gv UG & 1 & 770.49 & 770.49 & $180.12 *$ & .007 \\
\hline & Error & 26,678 & $114,119.57$ & 4.28 & & \\
\hline \multirow{2}{*}{$\begin{array}{c}\text { Gone to bed because could not } \\
\text { stay awake }\end{array}$} & Gv UG & 1 & 97.73 & 97.73 & $24.00^{*}$ & .001 \\
\hline & Error & 26,678 & $108,649.57$ & 4.07 & & \\
\hline \multirow{2}{*}{$\begin{array}{c}\text { Extremely hard time falling } \\
\text { asleep }\end{array}$} & Gv UG & 1 & 627.54 & 627.54 & $155.47^{*}$ & .006 \\
\hline & Error & 26,678 & $10,7687.40$ & 4.04 & & \\
\hline
\end{tabular}

Note: G v UG = Graduate vs. Undergraduate; ${ }^{*} p<0.001$

A multivariate GLM procedure was run with the five dependent variables that related to the number of days an individual experienced a sleep issue. Because of the high correlation between age and graduate versus undergraduate status $(\mathrm{r}=.41, p<.001)$, graduate/undergraduate status was the independent variable with age entered as a covariate. Differences were found in the overall model, Wilk's Lambda $=0.989, \mathrm{~F}(5,26,674)=60.43, \quad p<.001, \eta^{2}=.011$. Table 3 contains the item specific multivariate results for graduate versus undergraduate status. Age was also a significant factor in the overall model Wilk's Lambda $=0.990, \mathrm{~F}(5,26,674)=52.41, p<.001, \eta^{2}=.010$; however, only two item specific results were significant: "awakened too early" and "extremely hard time falling asleep." 
Table 4. Frequencies for perceived problems with sleepiness in the last 7 days*

\begin{tabular}{lrrr}
\hline & Graduate & Undergraduate & Total \\
\cline { 2 - 4 } No problem at all & $16.3 \%(481)$ & $9.3 \%(2212)$ & $10.1 \%(2693)$ \\
A little problem & $52.6 \%(1558)$ & $47.5 \%(11,269)$ & $48.1 \%(12,827)$ \\
More than a little problem & $19.8 \%(585)$ & $24.8 \%(5878)$ & $24.2 \%(6463)$ \\
A big problem & $8.0 \%(236)$ & $12.7 \%(3020)$ & $12.2 \%(3256)$ \\
A very big problem & $3.4 \%(100)$ & $5.7 \%(1342)$ & $5.4 \%(1442)$ \\
\hline $\mathrm{U}=29,592,617.00, \mathrm{Z}=-14.95, p<0.001$ & &
\end{tabular}

As shown in Table 4, for the ordinal level response item regarding participants' perception of sleep difficulties, graduate students significantly perceived having less sleep problems (Mann Whitney $\mathrm{U}=29,592,617.00, \quad \mathrm{Z}=$ $-14.95, p<.001)$.

\section{Discussion}

Research related to sleep disturbances has long cited that shifts to one's sleep-wake cycle can increase feelings of depression and difficulty concentrating (Taub \& Berger, 1974). Likewise, evidence has long suggested that sleep habits, particularly inconsistent wake-up times, can increase irritability and depression among college students (Taub, 1978) as well as significantly influence academic performance (Lack, 1986) and grade point averages (Gaultney, 2010; Taylor et al., 2011; Thacher, 2008; Trockel, Barnes, \& Egget, 2000). In the current study graduate students reported significantly less sleep problems within the last seven days than their undergraduate student counterparts. This is inconsistent with a previous small-sample study that found no differences in sleep patterns among classifications (Forquer et al., 2008); however, there are differences between the two studies. The 2008 study used validated instruments to measure sleep disturbance (Pittsburgh Sleep Quality Index6 and the Sleep Hygiene Test) with a sample of 300 from a single institution. The current study used six single item responses with a national sample of over 26,000 . While five of the six single items were measured together because of multicollinearity concerns; this is different than a validated instrument specifically designed to measure sleep disturbances. At the same, the small sample and single institution limit generalizability of the Forquer study.

The findings from the current study suggest that graduate students have better sleep hygiene than undergraduates. Sleep hygiene is defined as a variety of behaviors needed to have normal, quality nighttime sleep and full daytime alertness. Given the higher numbers of both work and volunteer hours graduate students perform, this finding may imply that graduate students are better able to manage their time and responsibilities. At the same time, Eden (2006) found no difference between work hours and excessive daytime sleepiness in her sample of undergraduate students.

Relationship status may also play a role in the difference between undergraduate and graduate students. Graduate students were more likely to be in a committed relationship and although the current study did not inquire about sleep patterns, Troxel's (2010) review indicates that those with a sleep partner frequently report better sleep patterns than those who do not have a sleep partner or when the sleep partner is not present. Similarly, others (Cacioppo et al., 2002) have found that lonely individuals have poor sleep patterns compared to those less lonely.

Perceived insufficient sleep and other sleep difficulties are correlated with other health conditions such as type II diabetes (Nedeltcheva \& Scheer, 2014), coronary heart disease, stroke, high blood pressure (Nedeltcheva \& Scheer, 2014), asthma, and arthritis (Liu et al., 2014). However being overweight/obese (Liu et al., 2014; Wheaton, Perry, Chapman, McKnight-Eily, Presley-Cantrell, \& Croft, 2011) and having frequent mental health distress (Liu et al., 2014) are more directly related to poor sleep habits than other health conditions. For example, Bixler et al., (2005) concluded that day time sleep is linked with depression in those under 30, and Prichard and colleagues' work (2013) shows high correlation between a psychiatric diagnosis and excessive sleepiness, sleep timing and sleep maintenance. As Wyatt and Oswalt (2013) report less frequent mental health issues in graduate students as compared to undergraduates, it is very likely that the sleep difference found in the current study is the result of mental health differences between graduate and undergraduate students. However the current study did not examine nor control for mental health issues or weight. Understanding how these other behaviors may affect graduate and undergraduate student sleep is needed in future research.

Likewise, the current study does not consider sleep disorders nor attempt to diagnosis sleep disorders among participants. Recent research by Petrov and colleagues (2014) indicated a high rate of sleep disorders among U.S. 
undergraduate students, but their research did not examine graduate students. Therefore it is unclear if the prevalence in sleep disorders could account for differences found in the current study.

While there may be underlying issues affecting sleep, even with the better sleep patterns reported by graduate students, they only received enough sleep to feel rested 1 out of every 2 days and felt tired and sleepy during the day on average 1 out of every 2.5 days. These rates still indicate sleep disturbances. From a higher education administration and student affairs perspective, colleges and universities must address the issue of sleep not only to improve the overall health, academic performance, and success of its undergraduate and graduate students but also to positively impact its retention rates (Gaultney, 2010).

\subsection{Implications for Practice}

Brown and Buboltz (2002) suggest the implementation of a student sleep education program as the most effective and least expensive means for addressing sleep difficulties. General guidelines for such a program include making students aware of the impact sleep difficulties can have on mood, attention span, academic performance, productivity, etc. as well as instructions for sleep hygiene. Students should understand the effects of caffeine, alcohol, napping, varied sleep schedules, and exercise on sleep problems (Brown \& Buboltz, 2002). Evidence demonstrates that in a population without sleep disturbances, this strategy increases knowledge of sleep hygiene which results in better sleep practices and consequently better sleep quality (Brown, Buboltz, \& Soper, 2006; Brown, Buboltz, \& Soper, 2002).

Sleep education can be incorporated into the preexisting programs of most colleges and universities, such as freshmen or graduate school orientation (Brown \& Buboltz, 2002). Some suggest colleges include a sleep screening and intervention early in students' academic experience in order to appropriately assess issues and provide needed referrals. As graduate students transition from an undergraduate environment to a graduate student schedule, information about sleep and its impact may facilitate better sleep hygiene.

One mechanism to facilitate sleep education is an online program. Quan and colleagues (2013) offered an online sleep module as part of an introductory psychology course; students showed improved sleep literacy and over half of the students also indicated behavior change (the most common change being a more consistent wake up time). A cognitive behavioral based sleep intervention that delivered pdfs via email to students also showed improvement in sleep patterns (Trockel, Manber, Change, Thurston, \& Tailor, 2011) and may be a cost-effective strategy. Similarly, A!Sleep from Alice Health Promotion at Columbia University is an example of an online sleep screening and education program designed to educate college students about the importance of sleep, provide strategies for enhancing sleep, and track sleep behavior patterns (Columbia University, 2012). As a service, Alice Health Promotion is willing to provide the programming code at no cost to other college health programs (McNeil, December 13, 2012). Regardless of the delivery method, if engaging in an online program, follow-up for those who are at risk for a sleep disorder and appropriate referral is a critical component (Gaultney, 2010).

Other programs combine sleep education with social marketing strategies and environmental programs. For example creating spaces around campus that are nap-friendly and creating awareness about such areas has been successful on one campus (Prichard et al., 2013). Graduate students may especially benefit from naps on campus with the potential for at home obligations (e.g. children, eldercare) that may prevent the opportunity for sleep at home. Eden (2006) also mentions establishing social norms around adequate sleep patterns. Based on Eden's work, one could suggest campus administrators work with graduate students and their faculty mentors to understand the impact of sleep issues on academic motivation.

These programs, whether mandatory or voluntary, can inform students of the important role of sleep in their personal and academic lives and consequently lead to better sleep habits. Unfortunately, the published work about programs again focusses on undergraduate students and the success of programs with graduate students is unknown and needs to be further studied. Researchers need to increase understanding of how these programs may or may not work for graduate students and part of that concerted focus will need to come from student affairs practitioners.

\subsection{Limitations}

There are some limitations in the current study. Other demographic factors were not examined. For example, previous research has indicated sex differences related to sleep, with women having better sleep in compared to men on many aspects; this seems especially true for women who are premenopausal (Bixler et al., 2009). As mentioned above, another study limitation is that sleep hygiene was not examined within the context of other mental health issues (Bixler et al., 2005; Liu et al., 2014; Prichard et al., 2013). Another limitation is the effect of age; while it only was a significant factor for two items after being controlled in the analyses, it was still a significant effect in the 
model. More detailed analysis on age and its connection to college student sleep is warranted. For example, one study found that healthy older adults (over 40 years of age) without sleep disorders can expect to be less sleepy during the daytime than individuals under 30 years old (Dijk, Groeger, Stanley, \& Deacon, 2010). At the same, in regards to age there is actually little research that looks at adolescents and middle age adults (Ohayon et al., 2004), so the role of age may not be as great within the total college student population. In addition, this study provides at least a first step to comparing and understanding the impact of age on sleep within the college setting.

\subsection{Conclusions}

Regardless of these limitations, this study still warrants attention as it focusses on the critical issue of sleep in graduate students. As campuses increasingly develop programs to ensure that the graduate student experience is positive (Border, \& von Hoene, 2010), sleep is certainly one of the issues that needs to be considered in the overall success of the student.

\section{Acknowledgement}

The opinions, findings, and conclusions presented/reported in this article are those of the author(s), and are in no way meant to represent the corporate opinions, views, or policies of the American College Health Association (ACHA). ACHA does not warrant nor assume any liability or responsibility for the accuracy, completeness, or usefulness of any information presented in this article/presentation.

\section{References}

American College Health Association. (2010a). About ACHA-NCHA: Participation History. Available at: http://www.acha-ncha.org/partic_history.html

American College Health Association. (2010b, September 10). American College Health Association - National College Health Assessment, Fall 2009 [computer file]. Baltimore, MD: American College Health Association [producer and distributor].

American College Health Association. (2004). National College Health Assessment: Reliability and validity analysis, 2000. Baltimore, MD: American College Health Association.

Bixler, E. O., Papaliaga, M. N., Vgontzas, A. N., Lin, H., Pejovic, S., Karataraki, M., Vela-Bueno, A. \& Chrousos, G. P. (2009). Women sleep objectively better than men and the sleep of young women is more resilient to external stressors: effects of age and menopause. Journal of Sleep Research, 18, 221-228. http://dx.doi.org/10.1111/j.1365-2869.2008.00713.x

Bixler, E. O., Vgontzas, A. N., Lin, H. M., Calhoun, S. L., Vela-Bueno, A., \& Kales, A. (2005). Excessive daytime sleepiness in a general population sample: The role of sleep apnea, age, obesity, diabetes, and depression. The Journal of Clinical Endocrinology \& Metabolism, 90, 4510-4515. http://dx.doi.org/10.1210/jc.2005-0035

Border, L. L. B. \& von Hoene, L. M. (2010). Graduate and professional student development programs. In K. J. Gillespie, D. L. Robertson (Eds.). A Guide to Faculty Development. (2nd Ed). (pp. 327-345). San Fransisco: Jossey-Bass.

Bray, N. J., Braxton, J. M. \& Sullivan, A.V. S. (1999). The influence of stress related coping strategies on college student departure decisions. Journal of College Student Development, 40(6), 37-41.

Brown, F. C. \& Buboltz, W. C. (2002). Applying sleep research to university students: Recommendations for developing a student sleep education program. Journal of College Student Development, 43, 411-16.

Brown, F. C., Buboltz, W. C., \& Soper, B. (2006). Development and evaluation of the Sleep Treatment and Education Program for Students (STEPS). Journal of American College Health, 54, 231-237. http://dx.doi.org/10.3200/JACH.54.4.231-237

Brown, F. C., Buboltz, W. C., \& Soper, B. (2002). Relationship of sleep hygiene awareness, sleep hygiene practices, and sleep quality in university students. Behavioral Medicine, 28, 33 - 38 . http://dx.doi.org/10.1080/08964280209596396

Buboltz, W. C., Brown, F., \& Soper, B. (2001). Sleep habits and patterns of college students: a preliminary study. Journal of American College Health, 50, 131-135. http://dx.doi.org/10.1080/07448480109596017

Buboltz, W., Jenkins, S.M., Soper, B., Woller, K., Johnson, P. \& Faes, T. (2009). Sleep habits and patterns of college students: an expanded study. Journal of College Counseling, 12 (2), 113-124. http://dx.doi.org/10.1002/j.2161-1882.2009.tb00109.x 
Bulmer, S. M., Irfan, S., Barton, B., Vancour, M. \& Breny, J. (2010). Comparison of health status and health behaviors between female graduate and undergraduate college students. Health Educator, 42 (2) 67-76.

Cacioppo, J.T., Hawkley, L.C., Berntson, G.G., Ernst, J.M., Gibbs, A.C., Stickgold, R. \& Hobson, J.A. (2002). Do lonely days invade the nights? Potential social modulation of sleep efficiency. Psychological Science, 13, 384-387. http://dx.doi.org/10.1111/1467-9280.00469

Centers for Disease Control and Prevention. (2011). Unhealthy sleep-related behaviors --- 12 States, 2009. Morbidity and Mortality Weekly Report (MMWR), 60(08);233-238.

Centers for Disease Control and Prevention. (2005). Percentage of adults who reported an average of $<6$ hours of sleep per 24-hour period, by sex and age group --- United States, 1985 and 2004. Morbidity and Mortality Weekly Report, 54(37), 933. Available at: http://www.cdc.gov/mmwr/preview $/ \mathrm{mmwrhtml} / \mathrm{mm} 5437 \mathrm{a} 7 . \mathrm{htm}$

Columbia University. (2012). A!Sleep. Helping you enhance your bedtime performance. Available at: http://sleep.health.columbia.edu/.

Dijk, D. J., Groeger, J.A., Stanley, N., \& Deacon, S. (2010). Age-related reduction in daytime sleep propensity and nocturnal slow wave sleep. Sleep, 33, 211-223.

Eisenberg, D., Gollust, S. E., Golberstein, E., \& Hefner, J. L. (2007). Prevalence and correlates of depression, anxiety, and suicidality among university students. American Journal of Orthopyschiatry, 77, 534-542. http://dx.doi.org/10.1037/0002-9432.77.4.534

Edens, K. M. (2006). The relationship of university students' sleep habits and academic motivation. Journal of Student Affairs Research and Practice, 43, 808-821. http://dx.doi.org/10.2202/1949-6605.1677

Forquer, L. M., Camden, A. E., Gabriau, K. M., \& Johnson, C. M. (2008). Sleep patterns of college students at a public university. Journal of American College Health, 56(5), 563-565. http://dx.doi.org/10.3200/JACH.56.5.563-565

Gallagher, R. (2011). National Survey of Counseling Center Directors. Alexandria, VA: International Association of Counseling Services; Monograph Series No. 8T.

Gaultney, J. F. (2010). The Prevalence of sleep disorders in college students: Impact on academic performance. Journal of American College Health, 59, 91-97. http://dx.doi.org/10.1080/07448481.2010.483708

Gilbert, S. P. \& Weaver, C. C. (2010). Sleep quality and academic performance in university students: A Wake-up call for college psychologists. Journal of College Student Psychotherapy, 24(4), 295-306. http://dx.doi.org/10.1080/87568225.2010.509245

Gradisar, M. \& Gardner, G., \& Dohnt, H. (2011). Recent worldwide sleep patterns and problems during adolescence: A review and meta-analysis of age, region and sleep. Sleep Medicine, 12, 110-118. http://dx.doi.org/10.1016/j.sleep.2010.11.008

Hyun, J. K., Quinn, B. C., Madon, T., \& Lustig, S. (2006). Graduate student mental health: needs assessment and utilization of counseling services. Journal of College Student Development, 47, 247-266. http://dx.doi.org/10.1353/csd.2006.0030

Lack, L. C. (1986). Delayed sleep and sleep loss in university students. Journal of American College Health, 35, 105-110. http://dx.doi.org/10.1080/07448481.1986.9938970

Liu, Y., Croft, J. B., Wheaton, A. G., Perry, G. S., Chapman, D. P., Strine, T. W., Mcknight-Eily, L. R. \& PresleyCantrell, L. (2013). Association between perceived insufficient sleep, frequent mental distress, obesity and chronic diseases among US adults, 2009 behavioral risk factor surveillance system. BMC Public Health, 13, 84. http://dx.doi.org/10.1186/1471-2458-13-84

McNeil, M. (2012, December 13). In S. Kenneally's [Sleep management responses]. https://listserv.utk.edu/cgi-bin/wa?A2=ind1212\&L=shs $\& \mathrm{~T}=0 \& \mathrm{~F}=\& \mathrm{~S}=\& \mathrm{X}=4 \mathrm{AA} 9 \mathrm{~A} 2499551300 \mathrm{~F} 25 \& \mathrm{P}=95811$, 2012

Meilman, P. W. (1993). Alcohol-induced behavior on campus. Journal of American College Health, 42(1), 27-31. http://dx.doi.org/10.1080/07448481.1993.9940453

Nedeltcheva, A. V., Scheer, F. (2014). Metabolic effects of sleep disruption, links to obesity and diabetes. Current Opinion in Endocrinology, Diabetes \& Obesity, 21, 293-298. http://dx.doi.org/10.1097/MED.0000000000000082 
Nelson, M. C., Lust, K., Story, M., \& Ehlinger, E. (2008). Credit card debt, stress and key health risk behaviors among college students. American Journal of Health Promotion, 22, 400-407. http://dx.doi.org/10.4278/ajhp.22.6.400

Ohayon, M. M., Carskadon, M. A., Guilleminault, C., \& Vitiello, M. V. (2004). Meta-analysis of quantitative sleep parameters from childhood to old age in healthy individuals: developing normative sleep values across the human lifespan. Sleep, 27, 1255-1274.

Orzech, K. M., Salafsky, D. B., \& Hamilton, L. A. (2011) The State of sleep among college students at a large public university. Journal of American College Health, 59, 612-619. http://dx.doi.org/10.1080/07448481.2010.520051

Petrov, M. E., Lichstein, K. L. \& Baldwin, C. M. (2014). Prevalence of sleep disorders by sex and ethnicity among older adolescents and emerging adults: Relations to daytime functioning, working memory and mental health. Journal of Adolescence, 37, 587-597. http://dx.doi.org/10.1016/j.adolescence.2014.04.007

Prichard, J. R., Cunningham, B., \& Broek, L. (2013, May). Enhancing college student sleep: Programming strategies that could work on your campus. Paper presented at the meeting of American College Health Association, Boston, MA.

Quan, S. F., Anderson, J. L., Hodge, G. K. (2013). Use of a supplementary internet based education program improves sleep literacy in college psychology students. Journal of Clinical Sleep Medicine, 9, 155-160. http://dx.doi.org/10.5664/jcsm.2414

Strahan, E.Y. (1999). The effects of social anxiety and social competence on undergraduate retention and academic performance. Dissertation Abstracts International: Section B. the Sciences and Engineering, 59(12-B), 6497.

Taub, J. M. (1978). Behavioral and psychophysiological correlates of irregularity in chronic sleep routines. Biological Psychology, 7, 37-53. http://dx.doi.org/10.1016/0301-0511(78)90041-8

Taub, J. M., \& Berger, R. J. (1974). Acute shifts in the sleep-wakefulness cycle: effects on performance and mood. Psychosomatic Medicine, 36, 164-173. http://dx.doi.org/10.1097/00006842-197403000-00008

Taylor, D. J., Vatthauer, K. E., Bramoweth, A. D., Ruggero, C., \& Roane, B. (2011). The role of sleep in predicting college academic performance: Is it a unique predictor? Behavioral Sleep Medicine Advance online publication. http://dx.doi.org/10.1080/15402002.2011.602776

Thacher, P. V. (2008). University students and the "All Nighter": Correlates and patterns of students' engagement in a single night of total sleep deprivation. Behavioral Sleep Medicine, 6(1), 16-31. http://dx.doi.org/10.1080/15402000701796114

Trockel, M. T., Barnes, M. S., \& Egget, D. L. (2000). Health-related variables and academic performance among first-year college students: implications for sleep and other behaviors. Journal of American College Health, 49, 125-131. http://dx.doi.org/10.1080/0744848000959629

Trockel, M., Manber, R., Change, V., Thurston, A., \& Tailor, C. B. (2011). An e-mail delivered CBT for sleep-health programs for college students: Effects on sleep quality and depression symptoms. Journal of Clinical Sleep Medicine, 7, 276-281. http://dx.doi.org/10.5664/jcsm.1072

Troxel, W. M. (2010). It's more than sex: Exploring the dyadic nature of sleep and implications for health. Psychosomatic Medicine 72, 578-586. http://dx.doi.org/10.1097/PSY.0b013e3181de7ff8

U.S. Department of Education National Center for Education Statistics. (2011). 2007 and 2009 Integrated Postsecondary Education Data System (IPEDS). Available at: http://nces.ed.gov/programs/digest/d10/tables/dt10_200.asp?referrer=list.

Wheaton, A. G., Perry, G. S., Chapman, D. P., McKnight-Eily, L. R., Presley-Cantrell, L. R., \& Croft, J. B. (2011). Relationship between body mass index and perceived insufficient sleep among U.S. adults: An analysis of 2008 BRFSS data. BMC Public Health, 11, 295. http://dx.doi.org/10.1186/1471-2458-11-295

Wyatt, T. J. \& Oswalt, S. B. (2013). Comparing mental health issues among undergraduate and graduate students. American Journal of Health Education, 44, 96-107. http://dx.doi.org/10.1080/19325037.2013.764248 